\title{
Comportamento ingestivo de cordeiras em pastagem consorciada de inverno sob diferentes intensidades de desfolha
}

\author{
Carine Lisete Glienke ${ }^{1}$, Marta Gomes da Rocha ${ }^{2}$, Anna Carolina Cerato Confortin ${ }^{1}$, Luciana \\ Pötter $^{3}$, Vagner Guasso da Costa ${ }^{1}$, Guilherme Ebling Rossi ${ }^{1}$
}

\footnotetext{
1 Programa Pós-graduação em Zootecnia, Universidade Federal de Santa Maria - UFSM, RS.

2 Departamento de Zootecnia - Universidade Federal de Santa Maria, RS.

3 UFSM/CESNORS - Palmeira das Missões.
}

RESUMO - Avaliou-se a relação entre a estrutura do pasto, as variáveis ambientais e o comportamento ingestivo de cordeiras Ile de France $\times$ Texel em pastagem consorciada de aveia-preta (Avena strigosa Schreb.), azevém (Lolium multiflorum Lam.) e trevo-vermelho (Trifolium pratense L.) sob quatro intensidades de desfolha (muito alta, alta, média e baixa). Utilizaram-se pastejos intermitentes considerando a soma térmica de 300 graus-dia como critério para determinar os intervalos de pastejo. As avaliações do comportamento ingestivo foram feitas por meio de observação visual em quatro períodos contínuos de 24 horas realizados no período de maio a outubro de 2006. O maior tempo de pastejo ocorreu na intensidade baixa. Altas intensidades de desfolha ocasionaram aumento da densidade populacional de perfilhos de azevém e não alteraram o peso desses perfilhos. A massa de bocados e a qualidade da dieta selecionada pelas cordeiras foram semelhantes entre as intensidades testadas. Em pastagem de aveia+azevém+trevo-vermelho, quando o intervalo de pastejo é determinado pela soma térmica de 300 graus-dia, a utilização de intensidades de desfolha que variam de baixa a muito alta não altera o comportamento ingestivo de cordeiras. O comportamento ingestivo é afetado pelo ciclo do pasto e pelo fotoperíodo e a seletividade dos animais reduz ao final do período de utilização da pastagem, quando ocorre aumento no tempo de pastejo e na distância percorrida em busca de locais de alimentação.

Palavras-chave: Avena strigosa, cordeiras, estações alimentares, Lolium multiflorum, tempo de pastejo, Trifolium pratense

\section{Ingestive behavior of lambs on mixed winter pasture under different grazing intensities}

\begin{abstract}
The relationship between the pasture structure, environmental variables and the ingestive behavior of crossbred Ile de France-Texel lambs on a mixed winter pasture of oats (Avena strigosa Schreb.), Italian ryegrass (Lolium multiflorum Lam.), and red clover (Trifolium pratense L.) under four grazing intensities ('very high', 'high', 'average', and 'low') was evaluated. Intermittent grazing was used, considering the thermal sum of 300 degree-days to determine the grazing interval. The evaluations of ingestive behavior were made by visual observation, in four continuous periods of 24 hours, conducted from May to October 2006. The highest grazing time occurred in 'low' grazing intensity. The 'high' grazing intensity increased Italian ryegrass density of tillers, without altering the tiller weight. The grazing intensity did not affect the bite weight and the diet quality selected by the animals. Using oats+Italian ryegrass+red clover pasture with a grazing interval determined by the thermal sum of 300 degree-day, grazing intensities can vary from 'low' to 'very high' without modify the lamb ingestive behavior. Ingestive behavior variables is affected by the grazing cycle and photoperiod. At the end of the grazing cycle the selectivity of the grazing animals is reduced, increasing both the time dedicated to grazing and the distance covered on the search for food patches.
\end{abstract}

Key Words: Avena strigosa, feeding stations, grazing time, lambs, Lolium multiflorum, Trifolium pratense

\section{Introdução}

O manejo adequado do pasto com oferta de forragem de qualidade pode tornar o sistema de produção de ovinos em pastagens cultivadas de inverno mais econômico e eficiente. O uso consorciado de forrageiras hibernais oferece benefícios como o aporte de $\mathrm{N}$ ao solo, proveniente da fixação biológica desse mineral pela leguminosa e da melhor distribuição de forragem durante o ciclo de produção. O cultivo da aveia-preta (Avena strigosa) nessas circunstâncias pode antecipar a utilização da pastagem, pois o pico de produção dessa forrageira é mais precoce que o 
de azevém (Lolium multiflorum Lam.). O trevo-vermelho (Trifolium pratense L.) pode prolongar o uso da pastagem, uma vez que seu pico de produção é mais tardio. A presença de mais de uma espécie forrageira, no entanto, torna o ambiente de pastejo mais complexo, dificultando o manejo do pasto, pois a ação seletiva dos animais influencia na participação proporcional dos componentes estruturais e botânicos da pastagem.

Em sistemas pastoris, as variáveis associadas ao pastejo são determinantes dos níveis de produção. Nesses sistemas, o desempenho do animal depende do consumo de forragem e dos efeitos dos processos de seleção e ingestão sobre a composição, estrutura e produtividade do pasto. Para atender suas exigências de ingestão de matéria seca, os herbívoros alteram o tempo de pastejo, a taxa e o tamanho de bocados. Assim, o estudo do comportamento ingestivo dos animais em pastejo pode auxiliar no entendimento da relação entre planta e animal.

O comportamento ingestivo do animal em pastejo pode ser afetado pela alteração da apreensibilidade da forragem, como conseqüência da intensidade de desfolha aplicada à pastagem. A intensidade interfere na disponibilidade de forragem ao animal e na formação da estrutura da pastagem; a resposta das plantas forrageiras a esse processo depende, portanto, da espécie, da severidade do processo de remoção de tecidos e da sua adaptação ao pastejo (Groff et al., 2002).

Este trabalho foi conduzido com o objetivo de estudar a relação entre as intensidades de desfolha, a estrutura da pastagem, o comportamento ingestivo de cordeiras e o processo de seleção de forragem na consorciação de aveia-preta, azevém e trevo-vermelho.

\section{Material e Métodos}

O experimento foi realizado no Departamento de Zootecnia da Universidade Federal de Santa Maria (UFSM), no período de maio a outubro de 2006. A área é localizada na região fisiográfica da Depressão Central do Rio Grande do Sul, com solo pertencente à unidade de mapeamento São Pedro, classificado como argissolo vermelho distrófico arênico (Embrapa, 1999). Na análise química do solo, realizada em amostras coletadas de 0 a $10 \mathrm{~cm}$ de profundidade, obtiveram-se os seguintes resultados: $\mathrm{pH}-\mathrm{H}_{2} \mathrm{O}=5$,4; \% argila $=19 \mathrm{~m} / \mathrm{V} ; \mathrm{K}=40 \mathrm{mg} / \mathrm{L} ; \% \mathrm{MO}=2,2 \mathrm{~m} / \mathrm{V} ; \mathrm{Al}=0,0 \mathrm{cmol} / \mathrm{L}$; $\mathrm{Ca}=6,4 \mathrm{cmol} / \mathrm{L} ; \mathrm{P}=6 \mathrm{mg} / \mathrm{dm}^{3} ; \mathrm{Mg}=2,7 \mathrm{cmol} / \mathrm{L} ; \mathrm{CTC} \mathrm{pH} 7=$ 16,1. A região possui clima subtropical úmido (Cfa), conforme classificação de Köppen (Moreno, 1961) (Tabela 1).

A área experimental utilizada, de $4.000 \mathrm{~m}^{2}$, foi dividida em quatro piquetes de $1.000 \mathrm{~m}^{2}$, e possuía $700 \mathrm{~m}^{2}$ de área
Tabela 1 - Temperatura máxima $\left(\mathrm{TMAX},{ }^{\circ} \mathrm{C}\right)$ e mínima $\left(\mathrm{TMIN},{ }^{\circ} \mathrm{C}\right)$, insolação (INS, horas) e horas do nascer (NAS) e pôrdo-sol (POS) nas datas de avaliação do comportamento ingestivo

\begin{tabular}{lccccc}
\hline Data & TMAX & TMIN & INS & NAS & POS \\
\hline $20 / 7 / 2006$ & 27,6 & 12,0 & 8,8 & $7: 20$ & $17: 32$ \\
$21 / 7 / 2006$ & 29,0 & 14,9 & 9,2 & $7: 20$ & $17: 32$ \\
$24 / 8 / 2006$ & 25,4 & 6,7 & 9,8 & $6: 49$ & $18: 05$ \\
$25 / 8 / 2006$ & 32,0 & 9,6 & 9,4 & $6: 48$ & $18: 06$ \\
$29 / 9 / 2006$ & 21,6 & 12,0 & 7,8 & $6: 05$ & $18: 25$ \\
$30 / 9 / 2006$ & 25,0 & 10,9 & 11,1 & $6: 04$ & $18: 25$ \\
$23 / 10 / 2006$ & 30,6 & 15,1 & 11,1 & $5: 38$ & $18: 40$ \\
$24 / 10 / 2006$ & 33,4 & 18,3 & 10,5 & $5: 37$ & $18: 41$ \\
\hline
\end{tabular}

anexa para permanência dos animais entre os períodos de avaliação.

A pastagem de aveia-preta (Avena strigosa Schreb.) e azevém (Lolium multiflorum Lam.) cv. Comum foi estabelecida no dia 18/5/2006, com preparo mínimo do solo, com uso de semeadora mecânica a lanço. Foram aplicados $250 \mathrm{~kg} / \mathrm{ha}$ da fórmula 5-20-20 (NPK), conforme recomendação da Comissão de Química e Fertilidade do Solo dos estados de Rio Grande do Sul e Santa Catarina (2004). As sementes de trevo-vermelho (Trifolium pratense L.) LE 116 foram tratadas com inoculante específico e peletizadas. A semeadura foi feita manualmente, a lanço, em 21/5/2006. As densidades de semeadura foram de 60, 30 e $10 \mathrm{~kg} /$ ha de sementes de aveia, azevém e trevo-vermelho, respectivamente. Aplicaram-se 22,5 kg/ha de N 45 dias após a semeadura e depois de cada pastejo, exceto no último, totalizando $90 \mathrm{~kg} / \mathrm{ha}$.

Na pastagem consorciada de aveia, azevém e trevovermelho, foram avaliadas quatro intensidades de desfolha por ovinos: muito alta = desaparecimento de matéria seca (MS) de 75\% do valor da massa de forragem inicial (MFI); alta = desaparecimento de 60\% da MFI; média = desaparecimento de $45 \%$ da MFI; baixa = desaparecimento de $30 \%$ da MFI

Os animais-teste foram 12 cordeiras obtidas do cruzamento entre as raças Ile de France $\times$ Texel com aproximadamente 8 meses de idade e peso médio de 26,2 \pm 3,3 kg em julho de 2006. Os animais tiveram acesso contínuo a água e sal mineral.

O critério adotado para a entrada dos animais no primeiro pastejo foi o valor da massa de forragem (MF) entre 1.500 e $2.000 \mathrm{~kg} / \mathrm{ha}$ de MS. Utilizaram-se pastejos intermitentes, com intervalos determinados pela soma térmica de 300 graus-dia, temperatura necessária para aparecimento de duas folhas de azevém (Quadros \& Bandinelli, 2005). A soma térmica acumulada no período foi calculada pelo 
somatório da temperatura média diária (TM), obtida a partir da fórmula (INMET, 2004):

$$
\mathrm{TM}=\left(\mathrm{T}^{\mathrm{O}} \mathrm{Mx}+\mathrm{T}^{\mathrm{o}} \mathrm{Mn}+\mathrm{T}^{\circ} 9 \mathrm{~h}+\left(2 \times \mathrm{T}^{\mathrm{o}} 21 \mathrm{~h}\right) / 5\right)
$$

em que $\mathrm{T}^{0} \mathrm{Mx}=$ temperatura máxima diária $\left({ }^{\circ} \mathrm{C}\right) ; \mathrm{T}^{0} \mathrm{Mn}=$ temperatura mínima diária $\left({ }^{\circ} \mathrm{C}\right) ; \mathrm{T}^{\circ} 9 \mathrm{~h}=$ temperatura às $9 \mathrm{~h}$; $\mathrm{T}^{0} 21 \mathrm{~h}=$ temperatura às $21 \mathrm{~h}$. Utilizou-se o valor de $5^{\circ} \mathrm{C}$ como temperatura base de crescimento (Cooper \& Tainton, 1968), diminuído da temperatura média diária.

A massa de forragem foi determinada por meio de cinco cortes rentes ao solo, realizados antes e depois de cada pastejo, em quadrados de $0,0625 \mathrm{~m}^{2}$ de área. Nas amostras provenientes dos cortes, foram determinados o teor de MS do pasto e sua composição botânica e estrutural, por meio da separação manual dos componentes folha de aveia e de azevém (lâmina), colmo de aveia e de azevém (bainha da folha + colmo), trevo (folíolo + pecíolo), material morto e outras espécies. Todas as amostras foram pesadas e secas em estufa de ventilação forçada a $55^{\circ} \mathrm{C}$, por 72 horas, para cálculo da proporção de cada componente botânico e estrutural, em \% da MS. A taxa de acúmulo de forragem (TAD, kg/ha/dia) foi obtida pela diferença entre o valor da massa de forragem antes do início de um novo pastejo e o valor da massa de forragem ao final do pastejo anterior, dividido pelo número de dias decorridos entre os dois.

A altura do pasto $(\mathrm{cm})$ foi medida em 20 pontos aleatórios, antes e depois de cada pastejo, por meio de caminhamento em diagonal nos piquetes, medindo-se a distância do solo até a altura média do dobramento das folhas das gramíneas. A diferença, em cm, entre a altura antes e depois da utilização do pasto foi denominada profundidade de pastejo.

Em cada piquete, foram demarcados três pontos fixos, delimitados por estacas, para avaliar as perdas de forragem (kg/ha/dia MS). Nesses pontos, depois de cada pastejo, foi colocado um quadrado e, na área delimitada $\left(0,0625 \mathrm{~m}^{2}\right)$, foi recolhido o material morto ou danificado por pisoteio e pastejo e que estava desprendido da planta. Esse material foi seco em estufa de ventilação forçada a $55^{\circ} \mathrm{C}$ por 72 horas e, posteriormente, pesado.

A adequação de carga foi realizada conforme descrito por Heringer \& Carvalho (2002). A carga animal (CA, kg/ha PV) foi calculada, em cada tratamento, de acordo com o percentual de desaparecimento da massa de forragem inicial (MFI), adotando-se como taxa de desaparecimento o valor de 4,5\% do peso vivo (PV) (3,0\% de consumo $+1,5 \%$ de perdas de forragem). Nas datas do início do pastejo, os animais eram pesados, após jejum de 12 horas, e identificados de acordo com sua participação em cada tratamento. O período de ocupação dos piquetes foi, em média, de quatro dias. A taxa de lotação, por avaliação, foi calculada por meio de divisão da conversão alimentar do piquete (kg/ha PV) pelo peso vivo médio dos animais-teste, de 26,2 $\pm 3,3$; $37,3 \pm 2,8 ; 43,7 \pm 2,7$ e 46,3 $\pm 2,6 \mathrm{~kg}$, respectivamente, no primeiro, segundo, terceiro e quarto pastejos.

O desaparecimento de forragem foi calculado conforme a equação:

$$
\mathrm{DF}=100-((\mathrm{MFF} \times 100) /(\mathrm{MFI}+\mathrm{TAD})),
$$

em que $\mathrm{DF}=$ desaparecimento percentual de forragem após pastejo; MFF = valor da massa de forragem no final do pastejo ( $\mathrm{kg} / \mathrm{ha}$ MS); MFI = massa de forragem no início do pastejo (kg/ha de MS); e TAD = taxa de acúmulo de forragem para o período.

As avaliações de comportamento ingestivo das cordeiras foram feitas por observação visual (Jamieson \& Hodgson, 1979) em quatro períodos contínuos de 24 horas, realizados em 20 e 21/6/2006, 24 e 25/8/2006, 29 e 30/9/2006 e 23 e 24/10/2006. Foram observados três animais-teste por piquete, identificados com brincos numerados e pintados para facilitar a observação. As atividades de pastejo, ruminação e ócio foram registradas em intervalos de 10 minutos. O tempo gasto pelos animais na seleção e apreensão da forragem, incluindo os curtos espaços de tempo utilizados no deslocamento para seleção da forragem, foi considerado tempo de pastejo (Hancock, 1953). O tempo de ócio correspondeu ao período de descanso e em outras atividades, como beber água e consumir sal, enquanto o tempo de ruminação correspondeu ao período de cessação do pastejo e de realização da mastigação. Por meio desses dados, foram calculados os tempos de pastejo, ócio e ruminação, em minutos/dia, que foram agrupados em períodos de 4 horas: das 1 às 7 h; das 7 às 13 h; das 13 às $19 \mathrm{~h}$; e de $19 \mathrm{~h}$ a $1 \mathrm{~h}$.

Durante o período diurno, para calcular a taxa de bocados/minuto, registrou-se, a cada 10 minutos, o tempo gasto pelo animal para realizar 20 bocados (Hodgson, 1982). Também foram registrados o tempo gasto pelo animal para percorrer dez estações alimentares e o número de passos entre essas estações. A estação alimentar foi definida como o espaço correspondente ao pastejo, sem movimentos das patas dianteiras (Laca et al., 1992), enquanto passo foi cada movimento das patas dianteiras. Esses dados foram utilizados no cálculo do número de estações e passos por minuto e do número de passos entre estações, classificados por período, manhã e tarde.

A coleta da forragem aparentemente consumida pelos animais em pastejo foi realizada por dois avaliadores treinados, que observaram uma cordeira-teste por piquete (Euclides et al., 1992). As amostras coletadas foram pesadas, secas em estufa de ventilação forçada a $55^{\circ} \mathrm{C}$, por 72 horas, 
e trituradas em moinho tipo Wiley com peneira de $1 \mathrm{~mm}$ para análises laboratoriais e determinação dos teores de proteína bruta, pelo método de Kjeldahl (método 984.13, AOAC, 1995), e de fibra insolúvel em detergente neutro (Van Soest et al., 1991).

Os valores de desaparecimento de forragem divididos pelo número de dias de cada período resultaram no desaparecimento diário de forragem. Esse valor, dividido pela carga animal e multiplicado por 100, foi denominado consumo estimado de forragem e expresso em \% PV. O valor do consumo estimado de forragem multiplicado pelo PV dos animais-teste originou o consumo estimado de forragem em $\mathrm{kg} / \mathrm{animal} / \mathrm{dia}$ de MS. A massa de bocado foi calculada pela divisão do consumo diário de MS pelo número diário total de bocados (taxa de bocados $\times$ tempo de pastejo; Jamieson \& Hodgson, 1979).

O delineamento experimental adotado foi o inteiramente casualizado, com parcelas sub-subdivididas no tempo. Os dados foram submetidos à análise estatística com análise de variância e teste $\mathrm{F}$ e, quando houve diferença entre as médias, aplicou-se o teste de Tukey, ambos a 5\% de significância. Realizou-se o teste de correlação e regressão polinomial a 5\% de significância. Os dados foram analisados utilizando-se o pacote estatístico SAS, versão 8.2 (2001).

\section{Resultados e Discussão}

A maior diferença, cinco pontos percentuais, entre o desaparecimento pretendido e observado ocorreu nas intensidades de desfolha baixa e muito alta (Tabela 2) nos valores extremos previstos para a desfolha (de 30 e $75 \%$ da MFI). A taxa de lotação foi estatisticamente maior $(\mathrm{P}=0,0001)$ na intensidade de desfolha muito alta e não diferiu entre as demais intensidades de desfolha, o que pode ser explicado pelo menor valor da massa de forragem inicial na intensidade de desfolha alta $(\mathrm{P}<0,0001)$, que permitiu a utilização de menor número de animais para alcançar a intensidade de desfolha prevista. Nas avaliações, o valor da massa de forragem inicial nas intensidades de desfolha de 35 e $70 \%$ foi semelhante, o que demonstra que, nessa amplitude de utilização, as intensidades de desfolha não alteraram a produtividade da consorciação, possivelmente em virtude do padrão seqüencial de crescimento das espécies utilizadas: aveia, azevém e, depois, trevo-vermelho.

A altura do pasto foi maior na intensidade de desfolha baixa e menor na intensidade de desfolha muito alta $(\mathrm{P}=0,0162)$. O pastejo foi realizado em maior profundidade $(\mathrm{P}=0,0001)$ na intensidade muito alta, $25,8 \mathrm{~cm}$, e em
Tabela 2 - Desaparecimento de forragem pretendido (DESp, \%) e observado (DESo, \%), taxa de lotação, massa de forragem inicial (MFI, $\mathrm{kg} / \mathrm{ha} \mathrm{MS}$ ) e altura inicial do pasto $(A L T, \mathrm{~cm})$ nas intensidades de desfolha em pastagem de aveia + azevém + trevo-vermelho

\begin{tabular}{lcccc}
\hline DESp & DESo & Taxa de lotação & MFI & AL T \\
\hline 30 & 35 & $36 \mathrm{~b}$ & $3.284 \mathrm{a}$ & $37 \mathrm{a}$ \\
45 & 43 & $37 \mathrm{~b}$ & $2.974 \mathrm{a}$ & $35 \mathrm{ab}$ \\
60 & 60 & $45 \mathrm{~b}$ & $2.437 \mathrm{~b}$ & $31 \mathrm{ab}$ \\
75 & 70 & $60 \mathrm{a}$ & $2.885 \mathrm{ab}$ & $27 \mathrm{~b}$ \\
\hline
\end{tabular}

Médias seguidas de letras diferentes na mesma coluna diferem $(P<0,05)$ entre si pelo teste Tukey.

profundidade menor na intensidade baixa $(\mathrm{P}=0,0001), 8,5 \mathrm{~cm}$, e foi semelhante nas demais intensidades (14,9 e 16,6 cm nas intensidades média e alta, respectivamente). A proporção de lâminas foliares removidas da massa de forragem foi, em média, de 56, 64, 75 e $86 \%$ nas intensidades de desfolha baixa, média, alta e muito alta.

Não houve diferença $(\mathrm{P}>0,05)$ na massa de componentes botânicos e estruturais da pastagem entre as intensidades testadas, exceto para o componente material morto, que apresentou maior participação na intensidade baixa, que não diferiu das intensidades média e muito alta, que, por sua vez, não diferiram da intensidade alta. Essa variação na massa de material morto está relacionada a diversos fatores, entre eles, o deslocamento e a seletividade do animal em pastejo (consumo de algumas espécies em detrimento de outras), o dano causado pelo pisoteio e as maiores taxas de senescência nas menores intensidades de desfolha.

Os componentes da pastagem de maior desaparecimento foram lâminas foliares de azevém (Tabela 3). A composição química da forragem aparentemente ingerida pelas cordeiras foi semelhante nas intensidades de desfolha testadas (PB: $\mathrm{P}=0,4385$; FDN: $\mathrm{P}=0,2357$ ), o que denota oportunidade igual para seleção da dieta.

A pequena redução na proporção de lâminas foliares de aveia no primeiro pastejo (Tabela 3) comprova que esse componente foi pouco selecionado pelas cordeiras no período inicial do pastejo. O trevo provavelmente foi pouco consumido, pois houve aumento de sua participação na massa de forragem após todos os pastejos. Assim, o uso da aveia na consorciação visando sua utilização pelos animais antes do azevém não foi eficiente, pois, no primeiro pastejo, houve desaparecimento proporcionalmente maior das lâminas foliares de azevém.

A composição química da forragem colhida pelas cordeiras diferiu nas datas de avaliação (PB: $\mathrm{P}=0,0008$; FDN: $\mathrm{P}=0,0120)$. Os teores de PB e FDN ajustaram-se aos modelos de regressão quadrático e cúbico, respectivamente (Figura 1). 
Tabela 3 - Participação percentual média de componentes botânicos e estruturais na massa de forragem da entrada (E) e saída (S) de cordeiras em pastagem de aveia+azevém+trevo-vermelho no período de julho a outubro de 2006

\begin{tabular}{|c|c|c|c|c|c|c|c|c|c|c|}
\hline \multirow[t]{3}{*}{ Avaliação ${ }^{1}$} & \multicolumn{4}{|c|}{ Aveia } & \multicolumn{4}{|c|}{ Azevém } & \multicolumn{2}{|c|}{ Trevo } \\
\hline & \multicolumn{2}{|c|}{ Lâmina } & \multicolumn{2}{|c|}{ Colmo } & \multicolumn{2}{|c|}{ Lâmina } & \multicolumn{2}{|c|}{ Colmo } & \multirow[b]{2}{*}{ E } & \multirow[b]{2}{*}{$\mathrm{S}$} \\
\hline & E & S & E & S & E & $S$ & E & $S$ & & \\
\hline 1 & 34,1 & 31,8 & 4,7 & 30,3 & 55,0 & 6,5 & 2,4 & 17,1 & 1,9 & 10,2 \\
\hline 2 & 20,8 & 4,8 & 33,3 & 35,2 & 23,4 & 16,1 & 7,8 & 16,8 & 0,7 & 1,7 \\
\hline 3 & 4,9 & 1,1 & 15,6 & 8,0 & 26,6 & 12,7 & 29,4 & 35,2 & 2,2 & 2,3 \\
\hline 4 & 0,0 & 0,0 & 0,0 & 0,0 & 11,7 & 5,8 & 43,4 & 39,0 & 6,2 & 7,8 \\
\hline
\end{tabular}

${ }^{1}$ Avaliações: 1 = 20 e 21/7/2006; 2 = 24 e 25/8/2006; 3 = 29 e 30/9/2006; 4 = 23 e 24/10/2006.

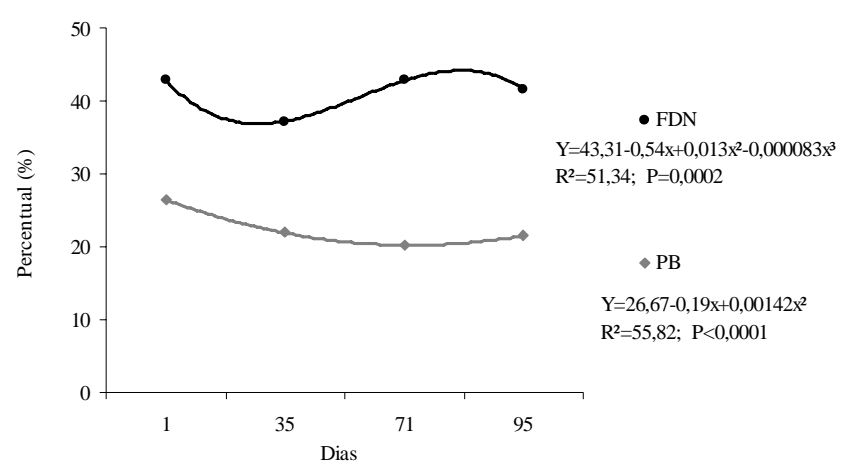

Figura 1 - Percentuais de FDN e PB da forragem aparentemente consumida por cordeiras em pastagem de aveia + azevém + trevo-vermelho.

A maior concentração de FDN na forragem ingerida ocorreu aos 76 dias e o menor teor de PB, aos 67 dias, períodos próximos ao terceiro pastejo, realizado aos 71 dias de utilização do pasto. Nessa data, encerrava a contribuição de aveia na massa de forragem e o azevém estava no final de seu ciclo, o que comprometeu a qualidade da forragem ofertada aos animas, em virtude da redução dos teores de carboidratos não-estruturais e do aumento dos teores de celulose, hemicelulose e lignina, característico do final do ciclo das gramíneas (Blaser, 1964).

O consumo preferencial de azevém influenciou $(\mathrm{P}=0,05)$ a densidade populacional de perfilhos (DPP) dessa espécie, que foi maior (2.100 perfilhos $\left./ \mathrm{m}^{2}\right)$ na intensidade alta, que não diferiu da muito alta (1.440 perfilhos) e da intensidade média (1.415 perfilhos), que, por sua vez, não diferiram da intensidade baixa (1.211 perfilhos $/ \mathrm{m}^{2}$ ). O peso dos perfilhos, assim como a densidade populacional do trevo-vermelho e da aveia, não diferiu entre as intensidades de desfolha. O peso médio dos perfilhos de azevém foi de $0,071 \mathrm{~g}$ de $\mathrm{MS}(\mathrm{P}=0,2124)$ e o peso médio das plantas de trevo foi de $0,047 \mathrm{~g}$ de MS $(\mathrm{P}=0,1831)$, com 151 plantas $/ \mathrm{m}^{2}$ $(\mathrm{P}=0,3377)$. A densidade populacional de perfilhos $(\mathrm{P}=0,3904)$ e o peso médio de perfilhos de aveia $(\mathrm{P}=0,2671)$ foram de 227 perfilhos/m² e 0,091 g de MS/perfilho.
O consumo estimado de MS foi semelhante $(\mathrm{P}=0,2090)$ nas intensidades de desfolha testadas e correspondeu a 5,9\% do PV, em média, valor superior ao encontrado no NRC para essa categoria, de 4,0\% do PV. O consumo foi estimado pelo método agronômico que superestima o seu valor, pois, na sua determinação, estão envolvidos possíveis erros na estimativa da produção inicial e final de forragem, na proporção de forragem oferecida e que é consumida, do crescimento da pastagem durante sua utilização e das perdas de forragem por senescência, pisoteio e consumo de animais não-experimentais (Minson, 1990).

Considerando que a taxa de desaparecimento foi de 6,5\% do PV para o consumo e as perdas médias estimadas de forragem de $5,9 \%$ e $0,6 \%$ do $\mathrm{PV}$, respectivamente, a estimativa da taxa de desaparecimento correspondente a $3,0 \%$ de consumo e $1,5 \%$ do PV de perdas (Heringer \& Carvalho, 2002) subestimou o consumo e superestimou as perdas, provavelmente por ter sido determinada com bovinos.

A massa de bocado foi semelhante nas intensidades de desfolha ( $\mathrm{P}=0,2760)$. Essa variável é a mais importante na determinação do consumo de animais em pastejo e a mais influenciada pela estrutura do dossel forrageiro (Hodgson, 1985). Nas estruturas do pasto formadas pelas intensidades de desfolha, não houve limitação na apreensão de forragem, pois o peso médio dos bocados foi de 0,152 g de MS, caracterizando bocados mais pesados que os realizados por ovelhas em pastejo contínuo em azevém, de 0,087 g de MS (Roman et al., 2007).

Não houve interação intensidades testadas $\times$ datas de avaliação $(\mathrm{P}>0,05)$ para os tempos de pastejo, ruminação e ócio (Figura 2).

O tempo de pastejo diferiu $(\mathrm{P}=0,0001)$ entre as intensidades de desfolha avaliadas (Figura 2A). Na intensidade baixa, o tempo de pastejo foi maior ( $\mathrm{P}=0,0001), 617,5$ minutos/ dia, apesar da maior disponibilidade de forragem em comparação às outras intensidades testadas. Como a composição química da dieta selecionada foi igual nas intensidades de desfolha, esse maior tempo de pastejo provavelmente foi 

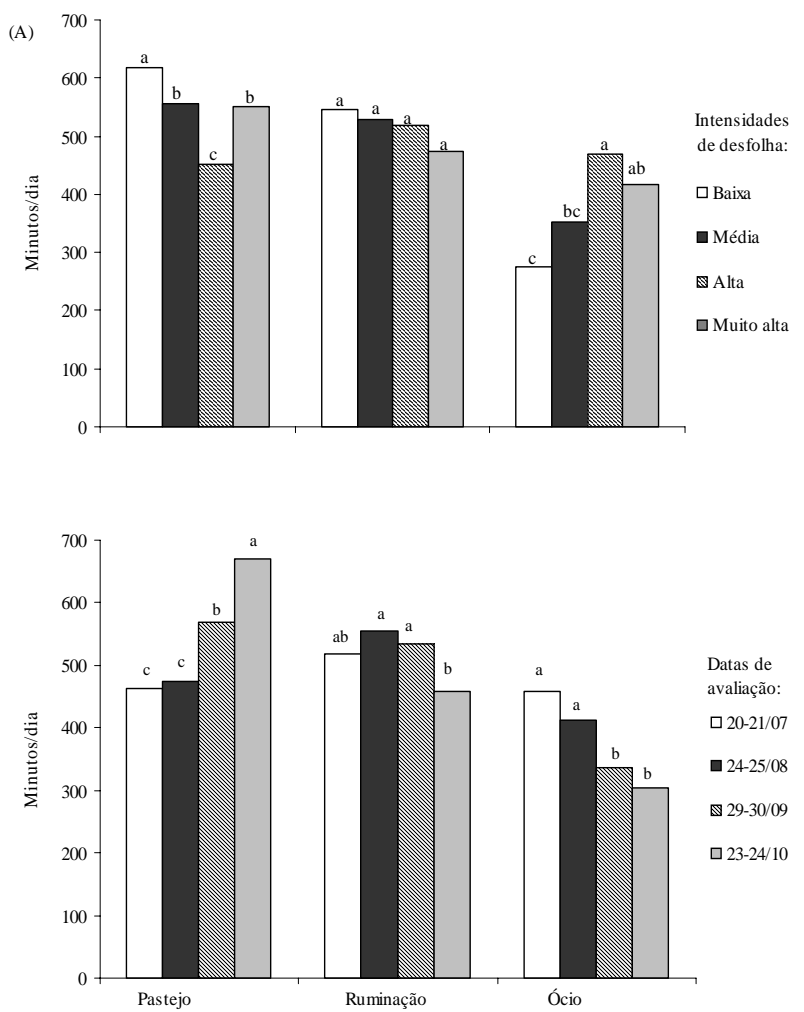

Baixa $=35 \%$ de desaparecimento; Média $=43 \%$ de desaparecimento; Alta $=60 \%$ de desaparecimento; Muito Alta $=75 \%$ de des aparecimento de MFI

Figura 2 - Tempo de pastejo, ruminação e ócio de cordeiras em pastagem de aveia + azevém + trevo-vermelho em diferentes intensidades de desfolha $(A)$ e nas datas de avaliação (B).

empregado para seleção dessa dieta. Na intensidade de desfolha alta, as cordeiras pastejaram por tempo menor ( $\mathrm{P}=$ 0,0001), 452,5 minutos/dia, provavelmente em decorrência da maior densidade populacional de perfilhos de azevém $(\mathrm{P}<0,05)$ e do menor valor da massa de forragem inicial $(\mathrm{P}=0,0028)$. A coleta diária de forragem pelos animais pode ter sido facilitada por esses dois parâmetros e, conseqüentemente, reduziu o tempo de pastejo. O mesmo tempo de pastejo $(\mathrm{P}>0,05)$ nas intensidades de desfolha média e muito alta provavelmente está relacionado à estrutura da pastagem.

As intensidades de desfolha testadas não ocasionaram diferença $(P=0,1010)$ no tempo de ruminação (Figura 2A), que é influenciado pela natureza da dieta, que foi semelhante nas intensidades de pastejo. Como as atividades do comportamento ingestivo são excludentes, a maior permanência dos animais em pastejo implicou redução do tempo de ócio, que diferiu entre as intensidades de utilização ( $P=0,0024)$ e entre datas de avaliação $(P<0,0001$, Figura 2B).

As datas de avaliação resultaram em diferenças nos tempos de pastejo $(\mathrm{P}<0,0001)$ e ruminação $(\mathrm{P}=0,0034)$. Os animais permaneceram mais tempo em pastejo no final do ciclo de utilização da pastagem (Figura 2B). Verificou-se, quando avaliadas as condições ambientais, correlação significativa $(\mathrm{P}<0,0001)$ entre o tempo diário de pastejo e os horários de nascer $(-0,69)$ e pôr-do-sol $(0,57)$ e o número de horas de insolação $(0,64)$. O período de pastejo foi maior $(\mathrm{P}<0,0001)$ no final do ciclo das forrageiras, quando ocorreram dias mais longos. Em condições de iluminação natural, em latitudes marcadas por um ritmo anual de fotoperíodo, ovinos apresentam ciclo diário de alimentação durante o ano, com pico no tempo de ingestão poucas semanas depois do dia mais longo e redução após o dia mais curto do ano (Forbes, 1995).

A composição estrutural do pasto no final do ciclo das espécies afetou o tempo de pastejo das cordeiras, que dedicaram mais tempo na procura e apreensão da forragem nas duas últimas datas de avaliação ( $\mathrm{P}<0,0001$, Figura 2B). Houve alta correlação entre tempo de pastejo e material morto ( $r=0,82 ; \mathrm{P}<0,0001)$. As outras correlações do tempo de pastejo ocorreram com folha de aveia $(r=-0,55, P<0,0001)$; colmo de aveia ( $\mathrm{r}=-0,33, \mathrm{P}=0,0195)$; folha de azevém $(\mathrm{r}=-0,52, \mathrm{P}=0,0001)$; colmo de azevém $(\mathrm{r}=0,58, \mathrm{P}<0,0001)$; trevo-vermelho $(\mathrm{r}=0,40, \mathrm{P}=0,0044)$.

Houve interação intensidades de desfolha $\times$ períodos para os tempos de pastejo $(\mathrm{P}<0,0001)$ e ócio $(\mathrm{P}<0,0001)$ (Figura 3). Na intensidade de desfolha baixa (Figura 3A), o tempo de pastejo ajustou-se ao modelo de regressão quadrático, com ponto de máximo às 9h6min. Nas demais intensidades de desfolha, o tempo de pastejo ajustou-se ao modelo cúbico de regressão, com pontos de máximo e mínimo pastejo às $12 \mathrm{~h} 14 \mathrm{~min}$ e 00h35min. Medeiros et al. (2007), no entanto, observaram maiores tempos de pastejo no final do período diurno.

O tempo de ócio (Figura 2B) ajustou-se ao modelo de regressão cúbico em todas as intensidades de desfolha. $\mathrm{O}$ ponto de mínima ocorrência do ócio ocorreu às 9h29min na intensidade baixa, às 9h57min na intensidade média, às 8h55min na intensidade alta e às 10h31min na intensidade muito alta. Na intensidade baixa, o ponto máximo de ócio ficou próximo ao de máxima atividade de pastejo, comprovando que, após o pastejo intenso no início da manhã, as cordeiras se mantiveram por um período em descanso, enquanto, nas demais intensidades, o período de ócio antecedeu o momento de máxima atividade de pastejo.

Não foi significativa a interação intensidades de desfolha $\times$ períodos do dia para o tempo de ruminação $(P=0,231)$. A atividade de ruminação ficou concentrada no período noturno, de modo que 37\% desta atividade ocorreu entre 0 h e 7 h. Carvalho et al. (2006) também observaram 38,78\% da atividade de ruminação entre 1 h e 6 h em cabras Alpinas. 

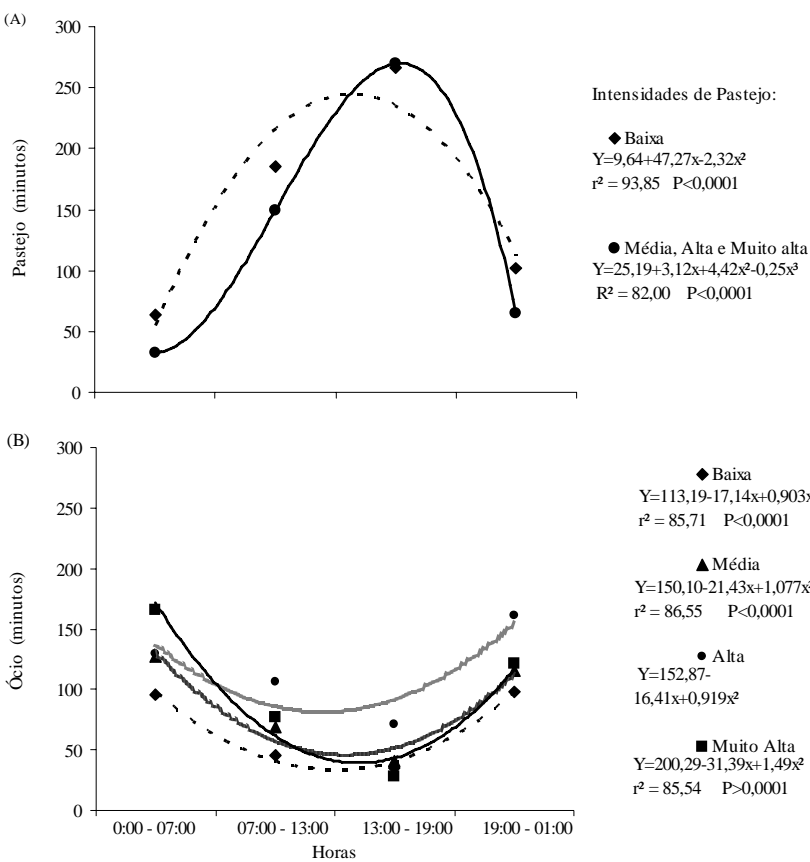

Baixa $=35 \%$ de desaparecimento; Média $=43 \%$ de desaparecimento; Alta $=60 \%$ de desaparecimento; Muito Alta $=70 \%$ de desaparecimento da MFI.

Figura 3 - Distribuição dos tempos de pastejo (A) e de ócio (B), em minutos, durante 24 horas, de cordeiras em pastagem de aveia + azevém + trevo-vermelho sob diferentes intensidades de desfolha.

A taxa de bocados foi influenciada pela interação intensidade de desfolha $\times$ data de avaliação $(\mathrm{P}=0,0022)$ e ajustou-se ao modelo de regressão cúbico (Figura 4) em todas as intensidades de desfolha.

Na comparação da variação no percentual de FDN (Figura 1) e da variação da taxa de bocados (Figura 3), as trajetórias desses dois parâmetros assemelharam-se no tempo, sugerindo que as maiores taxas de bocado ocorrem quando o teor de FDN é mais elevado.

O número de estações alimentares visitadas por minuto também foi influenciado $(\mathrm{P}=0,0208)$ pela interação intensidade de desfolha $\times$ data de avaliação (Tabela 4). Em média, as cordeiras visitaram 5,1; 4,1 e 5,0 estações/minuto na primeira, segunda e terceira avaliações, respectivamente. Na quarta avaliação, na intensidade de desfolha muito alta, as cordeiras dedicaram mais tempo ao pastejo na mesma estação alimentar, que não diferiu do tempo gasto na intensidade de desfolha baixa. O tempo de permanência dos animais nas estações alimentares é influenciado pela oferta de lâminas foliares verdes (Prache \& Rouguet, 1996), que provavelmente foi similar no final do ciclo do pasto nas intensidades extremas de desfolha. A distribuição de lâminas foliares e colmos no perfil das estruturas

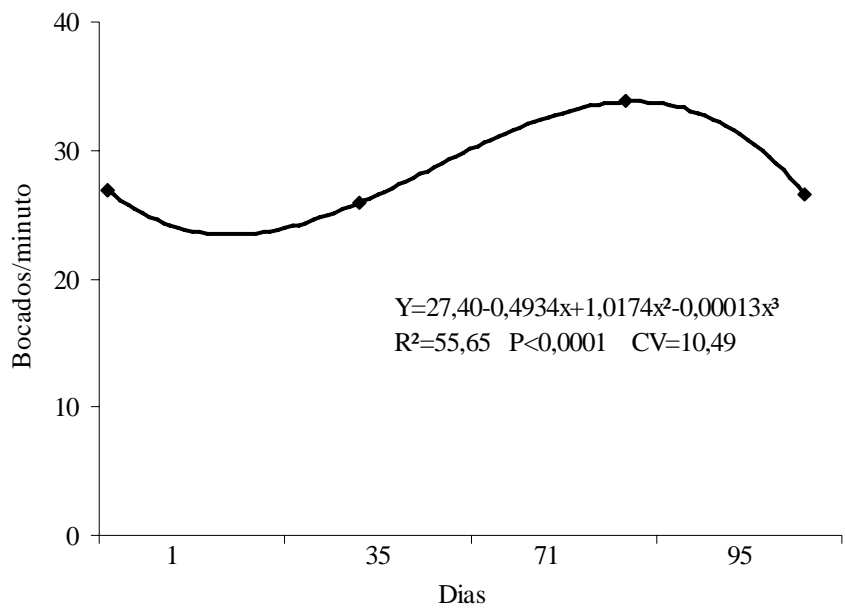

Figura 4 - Taxa de bocados de cordeiras em pastagem de aveia + azevém + trevo-vermelho sob diferentes intensidades de desfolha.

formadas nas intensidades baixa e muito alta provavelmente dificultou a apreensão da forragem pelas cordeiras, fazendo com que elas permanecessem mais tempo na mesma estação alimentar.

Não houve interação intensidades de desfolha $\times$ datas de avaliação para as variáveis passos/minuto e passos entre estações alimentares. As intensidades de desfolha e as datas de avaliação não influenciaram o número de passos por minuto (em média, foram dados 10,4 passos/ minuto). O número de passos entre estações sucessivas, no entanto, diferiu $(\mathrm{P}<0,0001)$ entre as datas de avaliação (Tabela 4).

A distância percorrida entre as estações alimentares é uma forma de mensurar a seletividade e, quanto maior essa distância, maior a seletividade (Roguet et al., 1998). As menores distâncias percorridas entre estações alimentares foram registradas durante o final do ciclo do pasto (Tabela 4), comprovando a menor oportunidade de seleção neste período, como conseqüência da alteração da composição estrutural do pasto, que reduz a presença de lâminas foliares.

Houve diferença no número de estações alimentares visitadas ( $\mathrm{P}>0,0238)$ durante os períodos da manhã e da tarde. No período da tarde, as cordeiras visitaram maior número de estações/minuto, 5,1, caminharam mais rápido ( $\mathrm{P}=$ 0,0237), 11,1 passos/minuto, e andaram mais entre estações sucessivas $(\mathrm{P}<0,0001), 2,6$ passos. Esses dados sugerem que o período da tarde é o momento de maior seletividade durante as 24 horas de pastejo. Trevisan et al. (2005) avaliaram ofertas de lâminas foliares em azevém pastejado por novilhos e não observaram diferença entre os 
Tabela 4 - Número de estações alimentares visitadas (estações/minuto) e passos dados por cordeiras entre estações sucessivas (PAS) em pastagem consorciada de inverno sob diferentes intensidades de desfolha

\begin{tabular}{lcccc}
\hline Intensidade de desfolha & \multicolumn{4}{c}{ Data de avaliação } \\
\cline { 2 - 5 } & 20 e $21 / 7 / 2006$ & 24 e $25 / 8 / 2006$ & 29 e $30 / 9 / 2006$ & 23 e $24 / 10 / 2006$ \\
\hline $35 \%$ & 5,6 & 4,1 & 5,2 & $4,2 \mathrm{cb}$ \\
$43 \%$ & 4,7 & 3,9 & 4,6 & 5,9 \\
$70 \%$ & 5,7 & 4,6 & 4,3 & $3,8 \mathrm{a}$ \\
$70 \%$ & 4,4 & 3,8 & $2,2 \mathrm{~B}$ & $1,9 \mathrm{~B}$ \\
\hline
\end{tabular}

Médias seguidas de letras minúsculas na coluna e maiúscula na linha diferem $(P<0,05)$ entre si pelo teste Tukey.

períodos da manhã e da tarde, nem entre datas de avaliação, para o tempo de permanência dos animais nas estações alimentares (em média, 18,6 segundos em cada estação).

\section{Conclusões}

No manejo da pastagem de aveia, azevém e trevovermelho, quando o intervalo entre pastejos é determinado pela soma térmica de 300 graus-dia, podem ser utilizadas intensidades de desfolha para remoção de 35 a $70 \%$ da massa de forragem inicial, pois essas intensidades de desfolha não alteram o comportamento ingestivo de cordeiras. O comportamento ingestivo é afetado pelo ciclo do pasto e pelo fotoperíodo, uma vez que a seletividade dos animais em pastejo reduz no final do ciclo, quando ocorre aumento no tempo dedicado ao pastejo e na distância percorrida em busca de estações alimentares.

\section{Literatura Citada}

ASSOCIATION OF OFFICIAL ANALYTICAL CHEMISTRY AOAC. Official methods of analysis. 16.ed. Arlington: AOAC International, 1995. 1025p.

BLASER, R.E. Symposium on forage utilization: effects of fertility levels and stage of maturity on forage nutritive value. Journal of Animal Science, v.23, p.246-253, 1964.

CARVALHO, S.; RODRIGUES, M.T.; BRANCO, R.H. et al. Comportamento ingestivo de cabras Alpinas em lactação alimentadas com dietas contendo diferentes níveis de fibra em detergente neutro proveniente da forragem. Revista Brasileira de Zootecnia, v.35, n.2, p.562-568, 2006.

COMISSÃO DE QUÍMICA E FERTILIDADE DO SOLO RS/SC (CQFS RS/SC). Manual de adubação e calagem para estados do Rio Grande do Sul e Santa Catarina. 10.ed. Porto Alegre: SBCS/NRS, 2004. 400p.

COOPER, J.P.; TAINTON, N.M. Light and temperature requirements for the growth of tropical and temperate grasses. Herbage Abstracts, v.38, p.167-176, 1968.

EMPRESA BRASILEIRA DE PESQUISA AGROPECUÁRIA EMBRAPA. Sistema brasileiro de classificação de solos. Rio de Janeiro. 1999. 412p.

EUCLIDES, V.P.B.; MACEDO, M.C.M.; OLIVEIRA, M.P. Avaliação de diferentes métodos de amostragem sob pastejo. Revista Brasileira de Zootecnia, v.21, n.4, p.691-702, 1992.
FORBES, J.M. Voluntary food intake and diet selection in farm animals. London: Centre for Agricultural and Biosciences Internacional, 1995. 532p.

GROFF, A.M.; MORAES, A.; SOUSSANA, J.F. et al. Intervalo e intensidade de desfolhação nas taxas de crescimento, senescência e desfolhação e no equilíbrio de gramíneas em associação. Revista Brasileira de Zootecnia, v.31, n.5, p.1912-1923, 2002.

HANCOCK, J. Grazing behaviour of cattle. Animal Breeding Abstract, v.21, n.1, p.1-13, 1953.

HODGSON, J. The control of herbage intake in the grazing ruminant. Proceedings of the Nutrition Society, v.44, p.339-346, 1985.

HERINGER, I.; CARVALHO, P.C.F. Ajuste da carga animal em experimentos de pastejo: uma nova proposta. Ciência Rural, v.32, n.4, p.675-679, 2002.

HODGSON, J. Ingestive behavior. In: LEAVER, J.D. (Ed.) Herbage intake handbook. Hurley: British Grassland Society, 1982. p.113-136.

INSTITUTO NACIONAL DE METEREOLOGIA - INM. Divisão de Observação Metereológica. Curso de atualização para observador metereológico de superfície. Porto Alegre, 2004. 57p.

JAMIESON, W.S.; HODGSON, J. The effect of variation in sward characteristics upon the ingestive behavior and herbage intake of calves and lambs under continuous stocking management. Grass and Forage Science, v.34, p.273-281, 1979.

LACA, E.A.; UNGAR, E.D.; SELIGMAN, N. et al. Effects of sward height and bulk density on bite dimensions of cattle grazing homogeneous swards. Grass and Forage Science, v.47, p.91-102, 1992.

MEDEIROS, R.B.; PEDROSO, C.E.S.; JORNADA, J.B.J. et al Comportamento ingestivo de ovinos em pastagem de azevém anual em diferentes estádios fenológicos. Revista Brasileira de Zootecnia, v.36, n.1, p.198-204, 2007.

MINSON, D.L. Forage in ruminant nutrition. San Diego: Academic Press, 1990. 483p.

MORENO, J.A Clima do Rio Grande do Sul. Porto Alegre: Secretaria da Agricultura, 1961. 41p.

NATIONAL RESEARCH COUNCIL - NRC. Nutrient requirements of sheep. 6.ed. Washington, D.C.: National Academy Press, 1985. 99p.

PRACHE, S.; ROGUET, C. Influence de la structure du couvert sur le comportement d'ingestion. Clermont-Ferrand: Institut National de la Recherche Agronomique, 1996. p.22-24. (Rapport d'Activité 1992-1995).

QUADROS, F.L.F.; BANDINELLI, D.G. Efeitos da adubação nitrogenada e de sistemas de manejo sobre a morfogênese de Lolium multiflorum Lam. e Paspalum urviellei Steud. em ambiente de várzea. Revista Brasileira de Zootecnia, v.34, n.1, p.44-53, 2005.

ROMAN, J.; ROCHA, M.G.; PIRES, C.C. et al. Comportamento ingestivo e desempenho de ovinos em pastagem de azevém anual (Lolium multiflorum Lam.) com diferentes massas de 
forragem. Revista Brasileira de Zootecnia, v.36, n.4, p.780-788, 2007.

ROUGET, C.; PRACHE, S.; PETIT, M. Feeding station behaviour of ewes in response to forage availability and sward phenological stage. Applied Animal Behaviour Science, v.56, p.187-201, 1998. STATISTICAL ANALYSIS SYSTEM - SAS. Statistical analysis system user's guide. Version 8.2. Cary: Statistical Analysis System Institute, 2001. (CD-ROM).
TREVISAN, N.B.; QUADROS, F.L.F.; SILVA, A.C.F. et al. Efeito da estrutura de uma pastagem hibernal sobre o comportamento de pastejo de novilhos de corte. Revista Brasileira de Zootecnia, v.34, n.3, p.774-780, 2005.

Van SOEST, P.J.; ROBERTSON, J.B.; LEWIS, B.A. Methods for dietary fiber, neutral detergent fiber, and nonstarch polysacharides in relation to animal nutrition. Journal of Dairy Science, v.74, p.3583-3597, 1991. 